\title{
Apical Domain of the Epithelium
}

National Cancer Institute

\section{Source}

National Cancer Institute. Apical Domain of the Epithelium. NCI Thesaurus. Code C32131.

The free part of the epithelium that faces the exterior surface or the lumen of an organ.

It may contain cytoplasmic processes (microvilli, stereocilia, and cilia). 